\title{
Cluster Development Models: Challenges and Opportunities
}

\author{
Md. Joynal Abdin ${ }^{1}$, Md. Mizanur Rahman ${ }^{2}$ \\ ${ }^{1}$ Program Officer, Planning, Monitoring and Evaluation Wing, SME Foundation, Dhaka, Bangladesh \\ ${ }^{2}$ Assistant Program Officer, Technology Development Wing, SME Foundation, Dhaka, Bangladesh
}

Email address:

mdjoynal@gmail.com (M. J. Abdin), rubel@smef.org.bd (M. M. Rahman)

\section{To cite this article:}

Md. Joynal Abdin, Md. Mizanur Rahman. Cluster Development Models: Challenges and Opportunities. International Journal of Economics, Finance and Management Sciences. Vol. 3, No. 4, 2015, pp. 358-366. doi: 10.11648/j.ijefm.20150304.15

\begin{abstract}
Clusters are the concentration of homogeneous enterprises producing similar products or providing identical services along with relevant backward and forward linkage enterprises in a particular geographic location sharing common opportunities and threats. Clusters are mainly two types based of their origin i.e. naturally grown and manmade clusters. Cluster development practitioners, experts, stakeholder organizations introduced a long list of cluster development models for guiding a cluster manager into his / her predetermined goal of cluster development. Notable models are provided by the United Nations Industrial Development Organization (UNIDO), Cluster Navigator - New Zealand, Cluster Plus - India, TCI Network - USA and European Cluster Observatory etc. None of the above mentioned model is fully implementable in a least developed country like Bangladesh. Bangladesh has limitations in terms of financial ability, technical knowledge, technological and managerial capacity to dedicate resources for cluster development. In Bangladesh enterprises are located at a particular location like cluster; but they do not have interlink either vertically or horizontally with each other. They are not sharing competitive advantages between them rather competing with each other's. As a result they are not enjoying expected growth by using advantages of a cluster. Therefore authors would like to analyze most of the available cluster development models and offer a new model titled J. M Model for Cluster Development. This model would be pro-poor, flexible and equally effective in any least developed country and developed economies as well. Basically, the model offered here is the result of the experiences of both the authors from needs assessment for cluster development and development initiatives for about thirty heterogeneous clusters located in different districts of Bangladesh. Each of the SME clusters are unique in nature with diverse opportunities and challenges. To address each of the challenge of cluster development the model shall be flexible enough for adopting tailor made intervention as and when required. This model will lead a practitioner into his or her predetermined goal of developing a naturally grown or man-made cluster.
\end{abstract}

Keywords: Cluster Development, Model for Cluster Development, Developing SME Clusters, Clustering Techniques, Strategies for Cluster Development

\section{Introduction}

Porter (2003) defines a cluster as a "Geographically proximate group of interconnected companies, suppliers, service providers and associated institutions in a particular field, linked by externalities of various types" [1]. Clusters contain a mix of industries related by knowledge, skills, inputs, demand, and other link ages. United Nations Industrial Development Organization (UNIDO) defines industrial cluster as: "Geographic and economic concentration of manufacturing activities which produce and sell a domain of interrelated and complementary products and having common problems and opportunities" [2]. Cluster could be defined based on different parameters like activities, origin, size wise, technology wise, linkage wise, market wise, state of development and based on entrepreneurs etc. For example manufacturing cluster or service providing cluster, naturally grown cluster or man-made cluster, growing cluster or declining cluster, export oriented cluster or domestic market based cluster etc. parameters could be used to define nature of a cluster.

Cluster development is comparatively a new term in Bangladesh. There was no uniform definition of clusters in Bangladesh till 2013. The small and medium enterprise Foundation (SME Foundation) defined SME clusters as "A 
Cluster is a concentration of 50 or above enterprises producing similar products or services and is situated within an adjoining geographical location of 3-5 kilometer radius and having a common strengths, weaknesses, opportunities and threats". Before that, Bangladesh Bank (the Central Bank or Bangladesh) published a short list of Clusters based on similar activities without any concrete definition of a cluster [3].

There are 177 SME Clusters in Bangladesh. Maximum 48 clusters belongs to Handicraft, 34 Agro-Processing/ Agribusiness/ Plantation, 31 Light engineering and metal working, 22 Knitwear \& RMG, 16 Fashion- rich wears, personal effects \& consumption goods, 13 Leather making \& leather goods, 10 Handloom, 5 Healthcare and diagnostic, 3 Plastic and other synthetic products, 3 Electronics and electrical, and 2 Educational service clusters in Bangladesh.

We are going to undertake and implement development interventions in the identified SME clusters in Bangladesh. Therefore we were searching for a suitable SME Cluster Development model to replicate and develop Bangladeshi clusters. All the identified clusters are naturally grown here based on availability of raw materials or skilled manpower or easy access to the consumers. We find difficulties to replicate any of the international models fully here in Bangladesh. Therefore we studied most the models of cluster development and would like to propose a new model could be suitable to implement here in Bangladesh and replicable in any other least developed country of the world. This model would be easy to understand without too much mathematical complexities, pro poor and flexible to replicate.

\section{Problem Statement and Research Question}

Cluster development is comparatively a new concept in Bangladesh. There are 8 Export Processing Zone (EPZ) in operation. Government is working to establish 5 Special Economic Zone (SEZ) in next two years. Difference between EPZ and SEZ is EPZ are only for export oriented industries, on the other hand SEZ will include the industries producing goods for local market. Government has to provide lands, electricity, gas, and water, transportation facility to develop a new EPZ or SEZ. Production plants will have to be newly established there with other backward and forward linkage industrial support. But existing SME clusters are having all these supports in hand and running with few limitations / barriers. Entrepreneurs are operating their business for several decades. They have production value chain of their own with demand and supply. Therefore it could be better to provide cluster development support in existing clusters for better return within shortest possible time.

How to develop a naturally grown cluster? What are the development interventions has to be taken for cluster development? In which stage of development we would say an SME cluster is in developed stage? All these questions could be address in this article. At the same time the article would like to offer a comprehensive cluster development model for the least developed countries like Bangladesh. It would like to analyze most of the available cluster development models and identify complexities we are facing to replicate. Offering solutions to those complexities and proposing a new model for cluster development is the ultimate goal of this article.

\section{Objective of the Study}

Major objectives of this research are to study most of the available models for cluster development. Analyzing the models and recommending a comprehensive implementable cluster development model for the least developed countries like Bangladesh. This model will be similarly adoptable for naturally grown spontaneous clusters or govt. / private initiated planned clusters.

\section{Methodology}

This paper is the result of a number of SME Cluster development initiatives in Bangladesh. Experiences of SME Cluster Mapping study in 2013 and assessment of development needs on $30 \mathrm{SME}$ clusters located at different 30 districts of Bangladesh. Secondary materials were collected and analyzed to identify a suitable cluster development model. As the initiatives have experienced difficulties in adopting any of the models here in Bangladesh, therefore the authors have developed a more customized model based of the needs assessment result and a series of focus group discussion (FGD) and key informant interviews (KII) of the stakeholders for Bangladeshi clusters.

\subsection{Scope of Work}

The authors are two key members of SMEF cluster development team having experiences in identifying and mapping SME Clusters. They have experiences for conducting needs assessment studies and census in various SME clusters within Bangladesh. They are searching for a suitable cluster development model to replicate in Bangladesh or some other like countries of similar economic condition. With this view in mind they have analyzed most of the cluster development models and recommended a new model for cluster development for least developed countries like Bangladesh.

\subsection{Limitation of This Study}

Main limitation of this model could be the uniqueness of this model. It is still in the primary stage of implementation. After completing every step in few clusters there may have need for think of the revision of this model. Of course, it will take ten to fifteen years' time to complete the whole development process in a cluster and to identify the faults and loop holes as well of this model. But this model has enough flexibility to adopt any new component or changes as and when required. 


\subsection{Literature Review}

"Industrial clusters can be defined as the localization of private firms producing similar and related products (e.g., final products and parts) [1]." - Otsuka and Sonobe (2011). In another statement we have found that, "Clusters are geographic concentrations of interconnected companies engaged in similar or highly related economic activities" (UNIDO, 2005a)

The definition of the term cluster has been the subject of much intellectual debate. A cluster is a grouping of likeminded companies (competitors) and talents in a specific geographic area. A feature of clusters is their statistically significant concentrations of companies and employment in relevant business activities that share common supply and distribution chains. Clusters generate considerable employment and are an important means of soaking up informal labor in cities (Kumral and Deger 2008).

Clusters can be broadly classified as-

(a) 'dormant'/'incipient'/ 'survival' clusters, those at an early stage of development, located where majority/significant percent of the population is poor and producing for local markets using simple technologies, and

(b) 'dynamic'/'matured'/'advanced mass production' clusters, which are more advanced in terms of technology and skills, often produce for global markets [4].

Clustered industrial economy is free from higher transactional costs as the entities are co-located in a similar economic and geographical zone [5]. There are essentially two components to cluster development; the first is cluster creation, the second cluster upgrading. Some experts claim that 'any effort to build clusters from scratch is doomed to failure' (Altenburg \& Eckhardt, 2005). Others believe that 'SME agglomerations [can] be created in green field areas [6].
Although many argue that, the low scale development of MSME entrepreneurs in most of the least developed countries are due to inadequate access to finance, but the major reason lie behind their development are low investment on human capital. Hence the provision of lowinterest loans to credit-constrained firms is more effective if it is implemented after the provision of technical and managerial training for them.

When discussing effective cluster development, a model must comply the changing pattern of labor-intensive to capital-intensive and further to knowledge-intensive policies for industries (Akamatsu 1962; Vernon 1966; Lin 2009). Hence the concept interlines with the technology transfer for developing countries from developed ones where it always results the successful development of the first (Hayami and Godo 2005).

To come up with a model for sustainable cluster development for LDCs like Bangladesh, it was very necessary to thoroughly study the existing models offered by many researchers with their own perspectives. Let's have a look into some of such models and our understandings with those.

\section{Different Models for Cluster Development}

\subsection{Cluster Development Model Offered by the Cluster Navigators, New Zealand}

According to Cluster navigators, the cluster development process has been built through the experience around the world and the researchers have refined the process to a Five Stage, Twelve Step process. The schematic diagram of the cluster development model could be shown as follows:

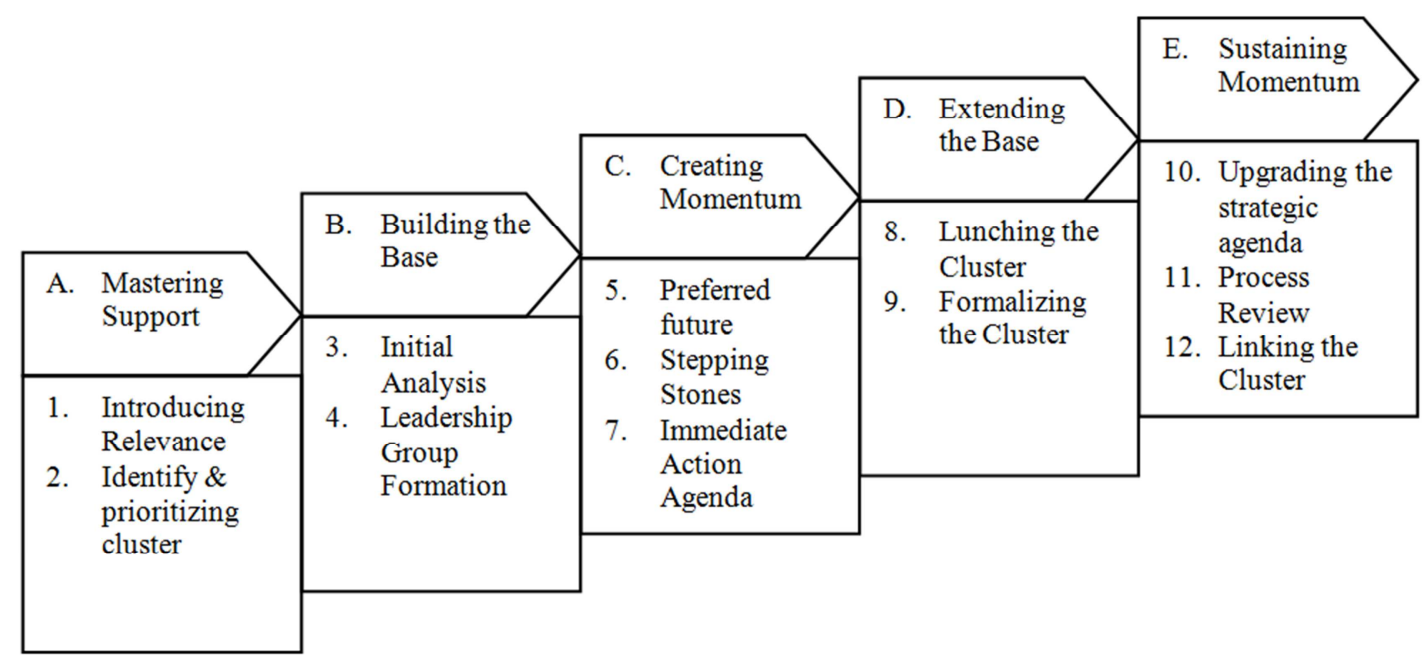

Source: Williams, I.F. (2005), Cluster Development: The How, TCI Annual Conference, Hong Kong.

Figure 1. Five Phase Twelve Steps Model for Cluster Development [7].

The cluster development process starts with the identification of clusters around the set geographical areas and in the first phase, the measure of support level is identified according to relevancy and priority for those 
clusters. During the second phase, within the selected clusters, thorough analysis is done and a leadership group who will take over the development process is formed. Next phase emphasizes upon the future goals to achieve, the milestones to reach and creating an agenda for taking actions for reaching those goals. In the fourth phase, the base is extended by launching and formalizing the cluster development initiatives. Finally, to sustain the development process, action plans are reviewed, upgraded and the cluster's business network is linked with internationally scattered similar or supportive clusters.

\subsection{The UNIDO Cluster Development Approach - Cluster Development in INDIA}

In a collaborative attempt, UNIDO and the Micro, Small and Medium Enterprise Ministry of India has started a new approach for the development of existing spontaneous clusters of India, started back in 2001. In this joint attempt, UNIDO lead the development process with a compact and vision oriented approach. For many clusters, this attempt had brought numerous successes. The whole approach can be shown as below:

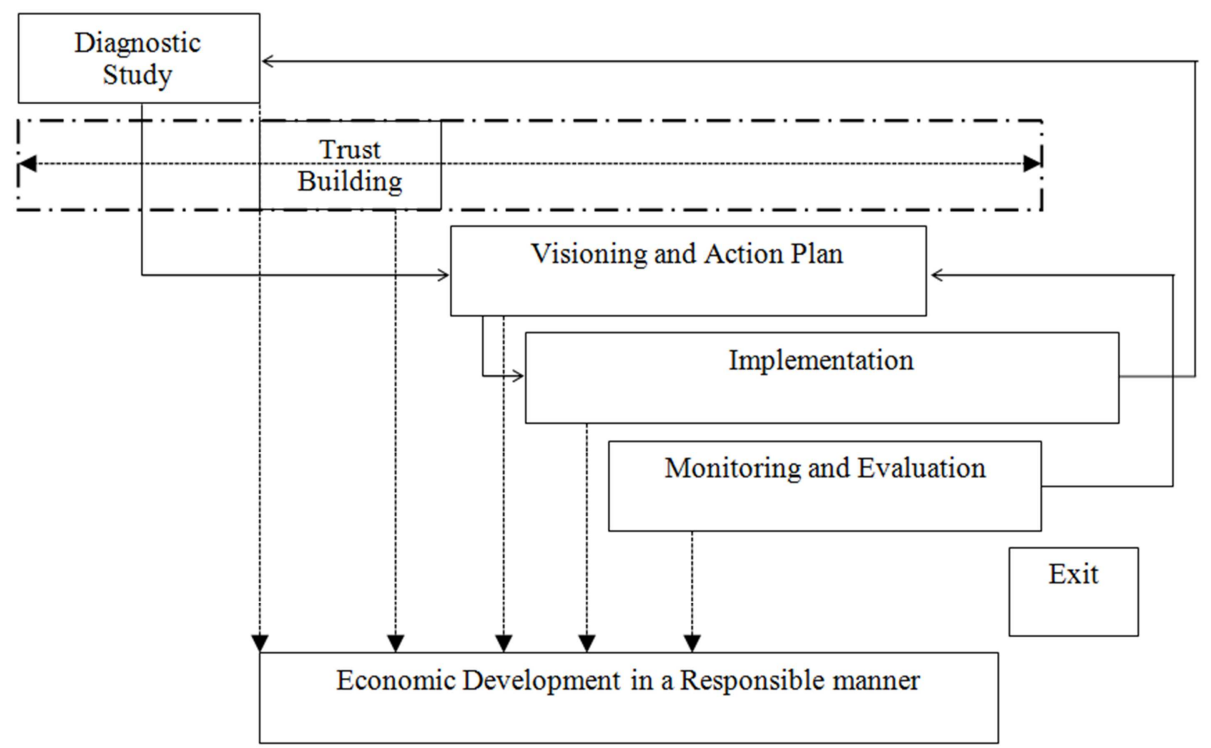

Source: Murali, B.P. Banerjee, S. (2011), Fostering Responsible Behavior in MSMEs in Clusters: Role of Cluster Development Agent, Volume. III, Foundation for MSME Clusters.

Figure 2. The UNIDO Cluster Development Approach-1 [8].

The phases of UNIDO approach could be shown as follows:

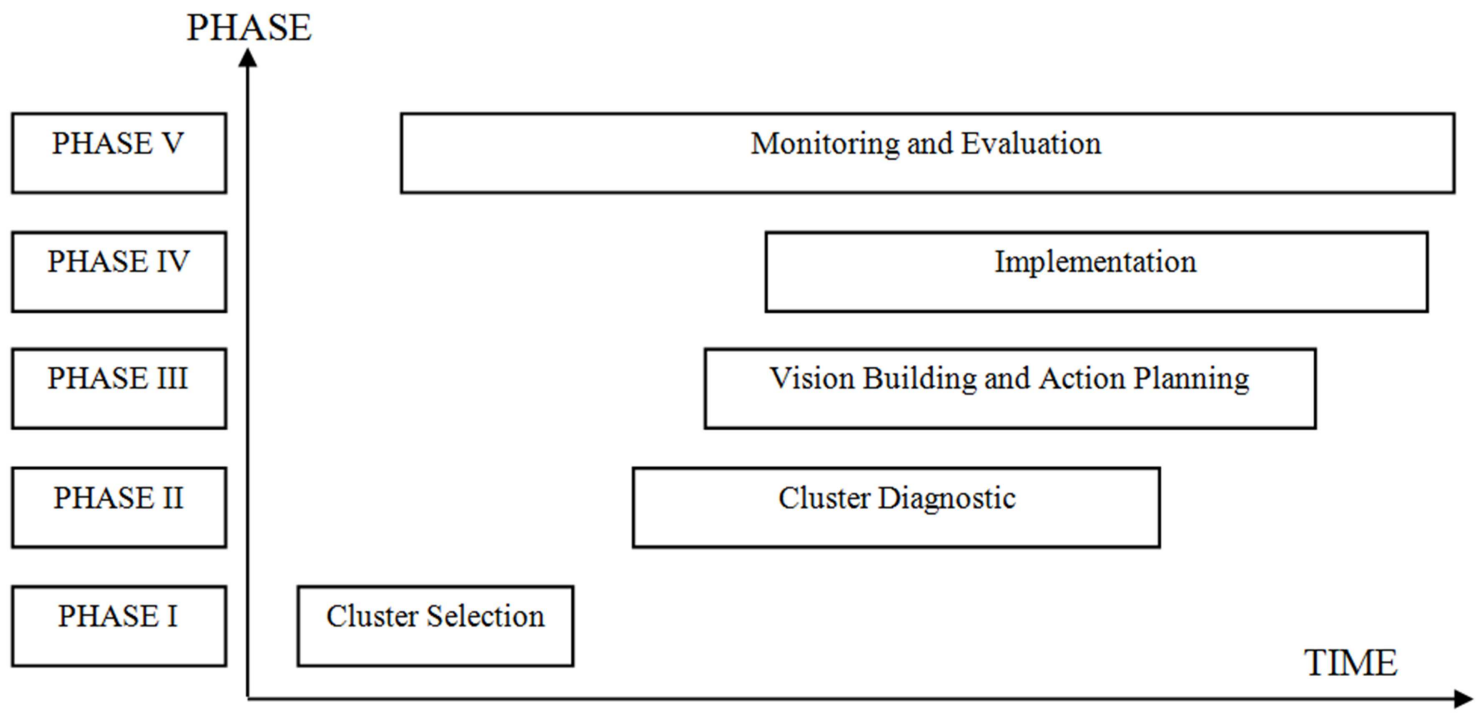

Source: Murali, B.P. Banerjee, S. (2011), Fostering Responsible Behavior in MSMEs in Clusters: Role of Cluster Development Agent,Volume. III, Foundation for MSME Clusters.

Figure 3. The UNIDO Cluster Development Approach-2. 
In Phase-I, during the cluster selection, in addition to potential for profit enhancement and demonstration effect, which clusters are dynamic, demonstrable opportunities and differentiable in terms of product and production process are considered to have high priority. Then the issues lie at the core of cluster underperformance is identified by a diagnostic study. Phase-III offers one-on-one meetings and informal workshops to extract points interesting but nonthreatening for handshake building among the cluster members. This process share and celebrate good practice to establish an atmosphere of trust among attendees. Later, more formal activities are planned, and more controversial issues are tackled. The action phase, identify activities with greatest benefits by calculating cost savings per firm from shared infrastructure, reduced training cost, decreased inspection and quality audit costs etc. through collective arrangements. Next phase targets the implementation of planned actions. All the actions are monitored and evaluated in the final phase for making corrections and upgradation of the process. In the very end, the exit is planned and the responsibility of entire development process is handed over the leadership group within the cluster.

\subsection{Cluster Development Approach in Republic of Croatia - Ministry of Economy, Labor and Entrepreneurship (MELE)}

Ministry of Entrepreneurship and Crafts (MoEC) of the Government of the Republic of Croatia led the Cluster development programs. But as many other Ministries and agencies were directly related to numerous clusters a comprehensive Cluster development strategy has to be taken, and now the existing strategy "Cluster Development Strategy in the Republic of Croatia 2011-2020 (April 2011)" was developed by the former Ministry of Economy, Labor and Entrepreneurship (MELE). In the process "Guidelines for Cluster Development-A Handbook for Practitioners" was published for the Ministry of Economy, Labor and Entrepreneurship (MELE) and Central Finance and Contracting Agency (CFCA) of the Government of the Republic of Croatia to aid in the cluster development approach. There, building a strategy, organization format and model of development of cluster was proposed, which was extensively guided the entire initiative of the Croatian Govt. According to the book two development models for clusters, i.e. Top-Down and Bottom-up approach of Building Clusters in Croatia are shown step-wise in a comparison chart.

Table 1. Cluster Development approach in Republic of Croatia [9].

\begin{tabular}{|c|c|}
\hline Top-Down Model & Bottom-Up Model \\
\hline STEP 1 & STEP 1 \\
\hline Analyse the Local Economy & Structure a Planning Framework \\
\hline $\boldsymbol{\nabla}$ & $\boldsymbol{\nabla}$ \\
\hline STEP 2 & STEP 2 \\
\hline Cluster Stock Taking & Cluster Vision / Mission and Values \\
\hline $\boldsymbol{\nabla}$ & $\nabla$ \\
\hline STEP 3 & STEP 3 \\
\hline Establish the Leadership Team & External and Internal Analysis \\
\hline $\boldsymbol{\nabla}$ & $\nabla$ \\
\hline STEP 4 & STEP 4 \\
\hline Cluster Vision and Mission & SWOT Analysis \\
\hline $\boldsymbol{\nabla}$ & $\nabla$ \\
\hline STEP 5 & STEP 5 \\
\hline Identify Stepping Stones & Brainstorm and Evaluation of Strategies \\
\hline$\nabla$ & $\nabla$ \\
\hline STEP 6 & STEP 6 \\
\hline Create Agenda of Immediate Actions & Select Option and Identify Result \\
\hline$\nabla$ & $\boldsymbol{\nabla}$ \\
\hline STEP 7 & STEP 7 \\
\hline Institutionalize the Cluster & Identify risk and critical factors \\
\hline $\boldsymbol{\nabla}$ & $\nabla$ \\
\hline STEP 8 & STEP 8 \\
\hline \multirow[t]{7}{*}{ Upgrade the Strategic Agenda } & Legalizing and Organizing \\
\hline & $\boldsymbol{\nabla}$ \\
\hline & STEP 9 \\
\hline & Draft Action Plans \\
\hline & $\boldsymbol{\nabla}$ \\
\hline & STEP 10 \\
\hline & Allocate Responsibility, implement and review \\
\hline
\end{tabular}

Source: Maxwell Stamp Plc. Prepared for the Ministry of Economy, Labor and Entrepreneurship (MELE), and the Central Finance and Contracting Agency (CFCA), Government of the Republic of Croatia, (2013), Guidelines for Cluster Development A Handbook for Practitioners. 
Major distinguishing fact between these two approaches are, the top-down approach is considered to be an initiative to develop a cluster strategy which comes from actors within sectors themselves, whereas the bottom-up approach envisages a cluster priority list on the basis of a cluster analysis to further the development.

\subsection{Development of Cluster Initiative - International Trade Department, World Bank}

This model was published in an article by ITD-World Bank, where we came to know about a 4-stage development approach for cluster initiatives. Following diagram will give a snapshot about the approach in short but in brief:

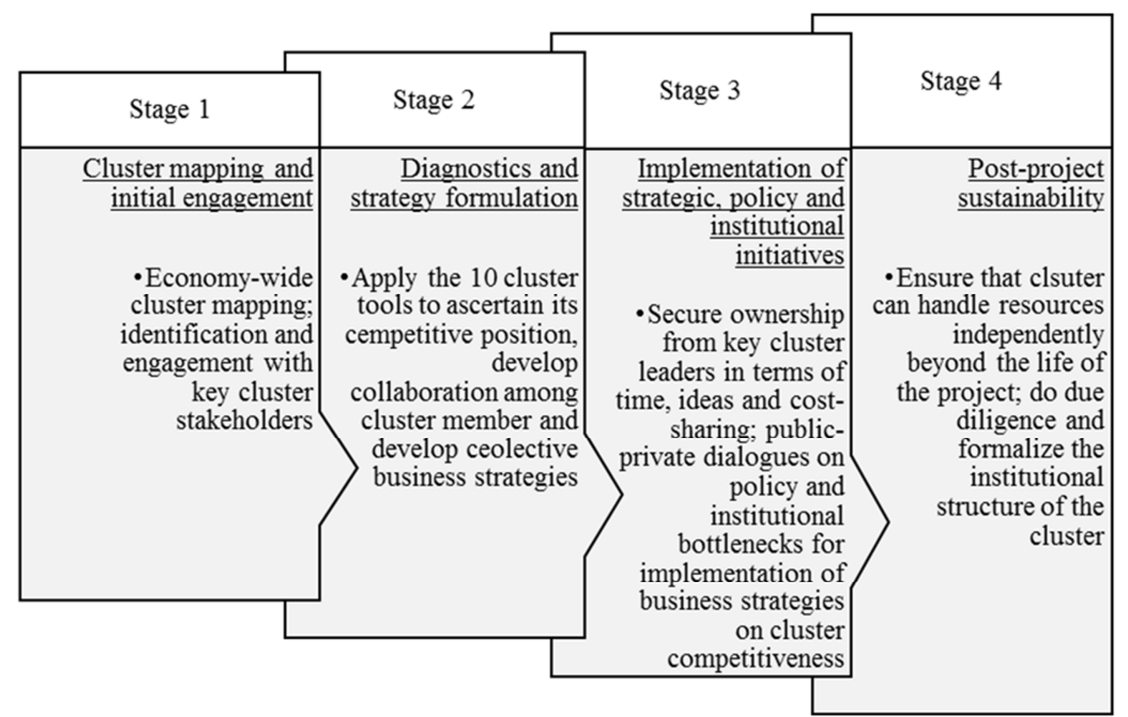

Source: World Bank, (2009), Cluster for Competitiveness- A Practical Guide \& Policy Implications for Developing Cluster Initiatives

Figure 4. Cluster Development Model, International Trade Department, World Bank [10].

Stage - 1 brings out the sketch-ups of each and every feature for a selected cluster by mapping all the inter-linkages among the stakeholders and flows of currency, goods and information within a single framework. After this job, the cluster is diagnosed and an effective strategy is thrown for developing that particular cluster. Many tools are used and many economic, social, technological and environmental attributes are measured for satisfying the finalization of the development strategy. Stage-3 focuses on implementation of the strategy taken. Also many policy-level and institutional initiatives are imposed for supporting the holistic development of that cluster. In final stage, a sustainable environment is left behind for maintaining the development in regular schedule.

An example of mapping a cluster according to this approach is shown below:

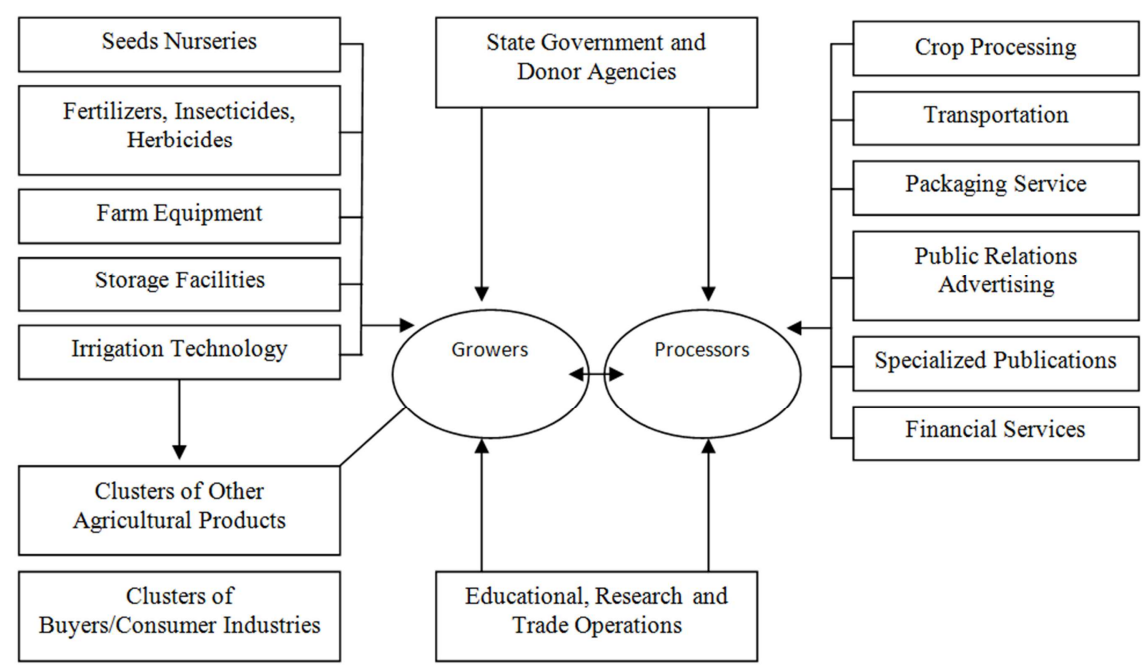

Source: World Bank, (2009), Cluster for Competitiveness- A Practical Guide \& Policy Implications for Developing Cluster Initiatives 


\subsection{Cluster Management Strategy by the European Cluster Observatory}

10 Steps towards a cluster management strategyis a simple proposition published in an article by Thomas L, Gerd M. and Michael N., the lead research group of European cluster observatory. The following diagram states the steps of this model. In this management strategy, the first step enables communication of the upcoming strategy process among the cluster participants viz. the entrepreneur and development partner followed by selection of stakeholders and cluster actors who are going to be involved. After a SWOT analysis for the cluster is followed focusing the current demand status and future expectations. In fourth step creativity workshops, competitions and brainstorming sessions are held with cluster actors and stakeholders to figure out possible options of development action.

Some new actors are involved in next step by interviewing. Many inefficient and ineffective strategic objectives and operational targets are deduced to narrow down the specific development goals. Next the action fields are identified and correlations among them are pointed out. A prioritization of actions and services is held next and discussed the whole approach with cluster actors and stakeholders. A formal agreement on action plan for development and implementation of support services is finally done with related actors and hereby cluster development rolls on.

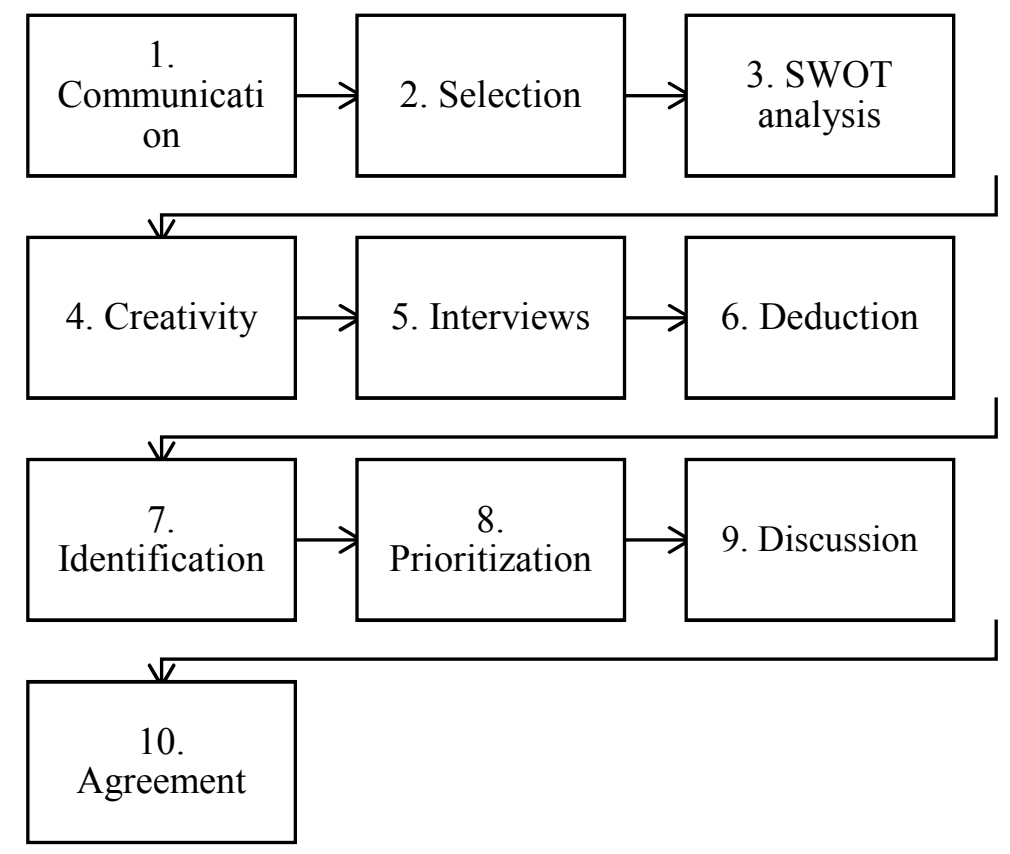

Figure 6. Cluster management strategy by the European Cluster Observatory [11].

Source: Gamp, T.L. Köcker, G.M. Nerger, M. (2014), Cluster Collaboration and Business Support Tools to Facilitate Entrepreneurship, Cross-sectoral Collaboration and Growth, European Cluster Observatory

\subsection{Cluster Based City Economic Development Concept- The Seven Steps CCED Analysis}

This concept of City Economic Development somehow relates the clustering approach in a mean of development base. It is result of collaborative research work on cities of three South Asian countries, viz. Bangladesh, India and SriLanka,and led by respective county experts. The concept focused the Porter's Competitive Advantages of Clusters for city economic development. The model schematically can be shown as follows:

Table 2. Cluster Based City Economic Development Concept [12].

\begin{tabular}{lll}
\hline I & Review national And Urban Development Strategy & Decide the scopes of urban areas \\
II & Assess Cities' Competitiveness & Select Cities \\
III & Evaluate Competitiveness of Multi-Sector Industries & Competitive industry prioritized \\
IV & Analyse Cluster Structure and GIS Mapping of Industry \\
Clusters & Evaluate Industry Clusters' Competitiveness and Deficiency \\
VI & Prepare Business and /or Action Plans & Select industry clusters in the selected cities \\
VII & Execute Project toward Competitive Cities and Industry & Indentify investment priorities \\
\hline
\end{tabular}

Source: Choe, K.Roberts B. (2011) Competitive Cities in 21st Century: Cluster based local economic development, Urban Development Series, ADB 
The kick-off reviews the existing urban and national development strategy to find the scopes of urban areas. Among the cities the most competitive cities are prioritized and selected to evaluate the competitiveness of existing multi-sector industries situated within those cities. Those industries which have the most competitiveness in some defined parameters are selected. Those industries within those cities are mapped with geographic information system to figure out the clusters. Then those cluster competitiveness and deficiencies are evaluated and various investment options are prioritized. After that, the implementable business/ action plan is prepared and executed according to priority. Finally the cluster is grown with networks and stabilized in a PPP platform to sustain the development.

Urban and industrial agglomerations have several advantages. Economies of scale (i) make it more efficient and effective to share market information, knowledge, new technology, product design and service innovations, and common research and development (R\&D) facilities or centers; and (ii) lower the costs of doing business. This is the key phenomenon behind the concept of cluster-based city economic development (CCED).

\section{Findings}

After a thorough discussion of the above mentioned cluster development models we cannotsum-up a concrete decision that, how a new cluster development group could develop a naturally grown / manmade cluster with limited resources. Each of the above models have focused a piecemeal scenario ofcluster development environments by emphasizing upon the thematic steps, required actions, intervention process, top down or bottom up approaches of interventions, resources mapping, tools and techniques, and community based clustering etc.

But none of the models have a first to last roadmap with required flexibilities to address new challenges could come up in different phases of steps. Therefore we would like to emphasis upon our practical experiences while working with clusters and sum up the available models into a concrete roadmap. It would be free from too much analytical complexities, smoother and interrelated steps with required flexibilities to address newer challenges could be come up in each steps. Our model have emphasized upon close monitoring, evaluation and required adjustment in each of the phases of cluster development.

\section{Proposed J.M Model forCluster Development}

As a matter of fact, almost all of the clusters situated in Bangladesh and other least developed countries identified so far are Co-located entrepreneurs. In this case, the development approach should follow by phases of identification through agglomeration and finally towards clustering. The following model could help a practitioner to guide toward his mission of developing a naturally grown SME cluster in a least developed economy.

Table 3. J.M. Model for Cluster Development.

\begin{tabular}{|c|c|c|c|c|c|}
\hline & Phase-I & Phase-II & PHASE - III & Phase-IV & Phase-V \\
\hline Phases & $\begin{array}{l}\text { Identification \& } \\
\text { Mapping }\end{array}$ & Cluster Analysis & $\begin{array}{l}\text { Intervention Designing } \\
\text { \& Piloting }\end{array}$ & $\begin{array}{l}\text { Implementation } \& \\
\text { Monitoring }\end{array}$ & $\begin{array}{l}\text { Networking \& } \\
\text { Evaluation }\end{array}$ \\
\hline Steps & $\begin{array}{l}\text { 1. Defining cluster as } \\
\text { per national stage of } \\
\text { industrialization, } \\
\text { 2. Identify cluster's } \\
\text { location in countries } \\
\text { administrative map } \\
\text { 3. Educating } \\
\text { Stakeholders with } \\
\text { the cluster } \\
\text { development process } \\
\text { 4. Developing a } \\
\text { database with cluster } \\
\text { information }\end{array}$ & $\begin{array}{l}\text { 5. Collecting data regarding } \\
\text { cluster's existing features, } \\
\text { development barriers, } \\
\text { potentials etc. through FGD } \\
\text { \& KII. } \\
\text { 6. Preparing Cluster's } \\
\text { Resource Map. } \\
\text { 7. Prioritizing cluster's } \\
\text { development barriers. } \\
\text { 8. Listing problems as per } \\
\text { short, mid and long term } \\
\text { basis. }\end{array}$ & $\begin{array}{l}\text { 9. Designing } \\
\text { development } \\
\text { interventions to } \\
\text { solve / overcome the } \\
\text { barriers. } \\
\text { 10. Identifying concern } \\
\text { agencies to take the } \\
\text { lead. } \\
\text { 11. Piloting a cluster } \\
\text { with identified } \\
\text { interventions. } \\
\text { 12. Monitoring outcome. } \\
\text { 13. Revising / updating } \\
\text { the list of } \\
\text { interventions as and } \\
\text { when required. }\end{array}$ & $\begin{array}{l}\text { 14. Implementing } \\
\text { determined } \\
\text { interventions at a } \\
\text { cluster. } \\
\text { 15. Monitoring output } \\
\text { 16. Fixing benchmark } \\
\text { 17. Initiative for further } \\
\text { value addition } \\
\text { 18. Preparing leadership } \\
\text { groups for future } \\
\text { course of action. }\end{array}$ & $\begin{array}{l}\text { 19. Networking with } \\
\text { local \& international } \\
\text { stakeholder } \\
\text { organizations. } \\
\text { 20. Evaluating progress } \\
\text { and taking } \\
\text { corrective measures. } \\
\text { 21. Handing over the } \\
\text { leadership into the } \\
\text { leadership group. }\end{array}$ \\
\hline Outputs & $\begin{array}{l}\text { Latest database of } \\
\text { Clusters across the } \\
\text { country }\end{array}$ & $\begin{array}{l}\text { Updated information about the } \\
\text { problems and prospects of each } \\
\text { cluster. }\end{array}$ & $\begin{array}{l}\text { Cluster Development } \\
\text { Action Plan }\end{array}$ & $\begin{array}{l}\text { A growing / developed } \\
\text { cluster }\end{array}$ & $\begin{array}{l}\text { A sustainable and well } \\
\text { established cluster with } \\
\text { value chain linkage }\end{array}$ \\
\hline
\end{tabular}

Source: A new model for cluster development proposed by the authors.

\section{Justification}

Cluster development is a combination of multidimensional / multispectralcountries of action requires active participations of different stakeholder's agencies. It is quite difficult to maintain the coordination and gettingin timecooperation from all stakeholders. A concrete model could help the practitioners to make the game fruitful, functional and result worthy. Therefor we would like to offer the above model to make the game pleasant and free from too 
much analytical complexities with enough room / flexibilities to adjust with newer scenarios based on the ground reality.

\section{Conclusion}

A good model for cluster development could guide the practitioners into a smooth and successful development of an identified cluster. The proposed J.M Model for Cluster Development could guide practitioners into a logical expectation and facilitate cluster development within a predetermined timeframe. Outputs of each of the phases needs to be closely monitored and evaluated to meet the final result accordingly. This model could have few limitations but there are scope for further improvement if any new dimensionscomes up in practice. But till now this could be the best option for the cluster development agent without too much analytical complexities.

\section{References}

[1] Porter, M.E.(2003), the Economic Performance of Regions, Regional Studies, 37, pp. 549-578.

[2] Small and Medium Enterprise Foundation, (2013), SME Clusters in Bangladesh.

[3] Bangladesh Bank, (Undated), Small and Medium Enterprise (SME) Credit Policies \& Programmes.
[4] Foundation for MSME Clusters, (2010), Pro-poor Cluster Development Methodology.

[5] Otsuka K. and Sonobe T. (September 2011), 'A Cluster-Based Industrial Development Policy for Low-Income Countries', GRIPS Discussion Paper 11-09, Tokyo, Japan.

[6] UNIDO, (2006), SME Clusters and Responsible Competitiveness in Developing Countries.

[7] Williams, I.F. (2005), Cluster Development: The How, TCI Annual Conference, Hong Kong

[8] Murali, B.P. Banerjee, S. (2011), Fostering Responsible Behavior in MSMEs in Clusters: Role of Cluster Development Agent, Volume. III, Foundation for MSME Clusters.

[9] Maxwell Stamp Plc. Prepared for the Ministry of Economy, Labor and Entrepreneurship (MELE), and the Central Finance and Contracting Agency (CFCA), Government of the Republic of Croatia, (2013), Guidelines for Cluster Development A Handbook for Practitioners.

[10] World Bank,(2009), Cluster for Competitiveness- A Practical Guide \& Policy Implications for Developing Cluster Initiatives

[11] Gamp, T.L. Köcker, G.M. Nerger, M. (2014), Cluster Collaboration and Business Support Tools to Facilitate Entrepreneurship, Cross-sectoral Collaboration and Growth, European Cluster Observatory

[12] Choe, K.Roberts B. (2011), Competitive Cities in 21st Century: Cluster based local economic development, Urban Development Series, ADB 